\title{
The Dual AngII/AVP Receptor Gene N119S/C163R Variant Exhibits Sodium-Induced Dysfunction and Cosegregates With Salt-Sensitive Hypertension in the Dahl Salt-Sensitive Hypertensive Rat Model
}

\author{
Nelson Ruiz-Opazo, ${ }^{1}$ Lyle V. Lopez, ${ }^{1}$ and Victoria L.M. Herrera ${ }^{1,2}$ \\ ${ }^{1}$ Whitaker Cardiovascular Institute, Boston, MA, USA \\ ${ }^{2}$ Section of Cardiology, Evans Department of Medicine, Boston University School of Medicine, \\ Boston MA, USA \\ Accepted December 5, 2001
}

\begin{abstract}
Background: Essential hypertension is a prevalent complex polygenic disease and a major risk factor for cardiovascular disease, the leading cause of death in developed countries. Because of its complex and multifactorial nature, its genetic determinants still remain largely unknown. The Dahl saltsensitive hypertensive rat model exhibits impaired sodium handling, which is hypothesized to play a key role in the pathophysiology of polygenic hypertension. Thus, genes associated with renal regulation of salt and water balance are a priori likely candidates for a causative role in hypertension pathogenesis. The functional properties and renalspecific expression of the recently characterized AngII/AVP receptor suggest a putative modulator role in tubular sodium and fluid reabsorption. Based on these observations, we investigated the potential involvement of the AngII/AVP receptor in salt-sensitive hypertension.

Materials and Methods: We performed cosegregation analysis of the AngII/AVP receptor locus with salt-sensitive hypertension in an F2 (Dahl S $\times$ Dahl salt-resistant [R]) hybrid male cohort characterized for blood pressure by radiotelemetry after 8 weeks of high salt challenge. Further molecular analysis was done to identify putative AngII/AVP receptor molecular variants that could account for the AngII/ AVP receptor involvement in salt-sensitive hypertension pathogenesis.
\end{abstract}

Results: The AngII/AVP receptor was mapped to rat chromosome 1, $1.7 \mathrm{cM}$ centromeric to the D1Rat188 marker by radiation hybrid mapping analysis. Quantitative trait locus (QTL) analysis detected a highly significant linkage of the AngII/AVP receptor locus with high blood pressure (LRS = 13.8, $p=0.0002)$. Molecular characterization of the Dahl S and Dahl R AngII/AVP receptor cDNAs revealed two amino acid substitutions in the Dahl S AngII/AVP receptor (N119S, C163R) when compared to the Dahl R AngII/AVP receptor. These mutations are associated with an increased receptor affinity for both ligands (AVP and AngII) and an enhanced $\mathrm{G}_{\mathrm{s}}$-coupling by the receptor resulting in increased activation of adenylate cyclase with concomitant increase in cAMP production.

Conclusions: The observed molecular dysfunction in the Dahl S AngII/AVP receptor is consistent with increased tubular sodium and fluid reabsorption observed in Dahl S rats. Interestingly, the AngII/AVPr locus is within the narrowed chromosome 1 QTL region for blood pressure detected in different rat intercross linkage analyses. Altogether, the data strongly suggest that the AngII/AVP receptor is a hypertension susceptibility gene in the Dahl $S$ rat model, as well as raises the hypothesis that it too underlies the chromosome 1 blood pressure QTL identified in other hypertension rat models.

\section{Introduction}

The kidney plays a primary role in hypertension pathogenesis in the Dahl salt-sensitive hypertensive rat model (1-3). Transplant studies have shown that the donor kidney determines the blood pressure phenotype in the bilaterally nephrectomized recipient (3). A similar situation has also been described in human renal transplant patients (3). These facts validate the analysis of genes expressed preferentially within the kidney as logical candidates for hypertension-susceptibility genes. Because the AngII/ AVP receptor is prominently expressed in renal epithelial cells $(4,5)$, and both AngII and AVP hormones

Address correspondence and reprint requests to: N. Ruiz-Opazo, Whitaker Cardiovascular Institute, Boston, MA 02118.

Phone: 617-638-4384; fax: 617-638-4066; e-mail: nruizo@bu.edu are both known to modulate tubular sodium and fluid reabsorption (6-14), we investigated whether this receptor could have a potential role in hypertension pathogenesis. The AngII/AVP receptor is coupled to adenylate cyclase and responds with equal sensitivity to AngII and AVP (4). Pharmacologic characterization defines this dual receptor as a novel $\mathrm{AT}_{1} / \mathrm{V}_{2}$ type of receptor (5). These receptor properties, in conjunction with its renal immunocytochemical distribution to the outer medullary thick ascending limb tubules and inner medullary collecting ducts (5), suggest that the AngII/AVP receptor could play a prominent role in renal tubular sodium and fluid reabsorption. Thus, it is intriguing to hypothesize that this dual receptor could mediate the coordination of two distinct blood pressure regulatory systems. 
To assess the putative role of the AngII/AVP receptor in hypertension pathogenesis, we performed genetic and molecular analyses in the Dahl S/Dahl R rat genetic model of salt-sensitive hypertension. The results reported here strongly suggest that the AngII/AVP receptor is a hypertension-susceptibility gene in the Dahl S rat model, thus providing impetus for the future investigation of its potential role in human essential hypertension.

\section{Materials and Methods}

Chromosomal Localization of the AngII/AVP Receptor Gene

To localize the AngII/AVP receptor gene within the rat genome, we conducted a radiation hybrid panel screening on a rat panel (Rat/Hamster RH panel RH07) obtained from Research Genetics (Huntsville, AL, USA). A 479-bp polymerase chain reaction (PCR) fragment (upstream primer: 5'-gtt-aca-gag-ctg-agggcc-tg-3'; downstream primer: 5'-cct-gga-aac-cacact-cac-ct-3') from the $5^{\prime}$ regulatory region of the rat AngII/AVP receptor gene was utilized as indicator product. The data were then tested against the existing framework maps. The results assign the AngII/AVP receptor gene to chromosome 1, $14.6 \mathrm{cR}$ from D1Rat111 with a LOD $=24.673$. This places the AngII/AVP receptor gene approximately 1.7 cM centromeric to D1Rat188 (Table 1).

\section{Intercross Linkage Analysis}

The development of the (Dahl S/Hsd $\times$ Dahl R/Hsd) F2 male cohort and phenotypic characterization has been described previously (15). Blood pressure measurements were obtained by radiotelemetry after 8 weeks of high salt $(8 \% \mathrm{NaCl})$ challenge. Genotyping was performed using the following microsatellite markers: D1Rat68, D1Rat129, D1Rat188, D1Mgh11, D1Rat298, D1Rat371, D1Rat77, D1Rat304, and D1Rat122 obtained from Research Genetics. Linkage maps and QTL analysis were done with the Map Manager QTXb08 (MMQTX08) program for windows (16), which generates a likelihood ratio statistic (LRS) as a measure of the significance of a possible QTL. Genetic distances were calculated using Kosambi mapping function (genetic distances are expressed in $\mathrm{cM}$ ) and were as follows: D1Rat68 - (7.7, LOD $=25.0)-D 1$ Rat129 $-(6.6$, LOD $=27.3)-D 1$ Rat188 $-(0.5$, LOD $=$ 44.2) - D1Mgh11 - (10.5, LOD = 21.8) - D1Rat298 $(7.2, \quad$ LOD $=28.3)-$ D1Rat371 $-(4.5, \quad$ LOD $=34.2)-$ D1Rat77 $-(4.0$, LOD $=33.8)-$ DlRat304 $-(11.5$, LOD $=$ 20.4) - D1Rat122. Critical significance (LRS) values for interval mapping were determined by a permutation test (2000 permutations at 5 -cM intervals) on our 105 informative progeny using Kosambi mapping function and a constrained additive regression model. Thus, the minimum LRS values were 1.4 for suggestive, 6.6 for significant, and 12.2 for highly significant.

cDNA Library Screening and Nucleotide Sequencing

Dahl S/JR and Dahl R/JR rat kidney $\lambda$ gt 11 cDNA libraries (17) were screened with the full-length Sprague-Dawley AngII/AVP receptor cDNA (4). Several Dahl $S$ and Dahl $R$ AngII/AVP receptor

Table 1. QTL analysis of rat chromosome 1 for blood pressure in the F2 (Dahl $S \times$ Dahl R) intercross

\begin{tabular}{|c|c|c|c|c|c|c|c|c|c|}
\hline \multirow[b]{2}{*}{ Locus (Distance, cM) } & \multicolumn{3}{|c|}{ SBP } & \multicolumn{3}{|c|}{ DBP } & \multicolumn{3}{|c|}{ MAP } \\
\hline & LRS & $\%$ & $p$ & LRS & $\%$ & $p$ & LRS & $\%$ & $p$ \\
\hline D1Rat68 (0.0) & 7.1 & 6 & 0.00756 & 5.5 & 4 & 0.01926 & 7.0 & 6 & 0.00802 \\
\hline D1Rat129 (7.7) & 11.0 & 9 & 0.00090 & 6.9 & 6 & 0.00839 & 10.2 & 9 & 0.00138 \\
\hline \multicolumn{10}{|l|}{ AngII/AVPr (4.9) } \\
\hline D1Rat188 (1.7) & 13.8 & 12 & 0.00020 & 8.6 & 7 & 0.00336 & 12.4 & 10 & 0.00043 \\
\hline D1Mgh11 (0.5) & 13.6 & 11 & 0.00023 & 8.8 & 7 & 0.00298 & 12.4 & 10 & 0.00042 \\
\hline D1Rat298 (10.5) & 5.4 & 4 & 0.02047 & 3.1 & 2 & 0.07786 & 4.8 & 4 & 0.02921 \\
\hline D1Rat371 (7.2) & 3.1 & 2 & 0.07920 & 1.8 & 1 & 0.18290 & 2.9 & 2 & 0.08596 \\
\hline D1Rat77 (4.5) & 2.7 & 2 & 0.09800 & 1.4 & 0 & 0.23236 & 2.5 & 1 & 0.11497 \\
\hline D1Rat304 (4.0) & 2.2 & 1 & 0.13659 & 0.6 & 0 & 0.43679 & 1.6 & 1 & 0.20576 \\
\hline D1Rat122 (11.5) & 1.1 & 0 & 0.30434 & 0.2 & 0 & 0.67527 & 0.6 & 0 & 0.44267 \\
\hline
\end{tabular}

BP, blood pressure; SBP, systolic; DBP, diastolic; MAP, mean arterial pressure; LRS, likelihood ratio statistic for the association of the trait with loci; \%, the amount of the total trait variance that would be explained by a QTL at these loci, as a percent; $p$, probability value for the association.

Statistical values presented are derived from regression analysis based on an additive model of inheritance using the MapManager QTXb08 program. The additive model fitted best, thus defining the dominance properties of the QTL. Genetic distances are presented in parenthesis in cM. The localization of the AngII/AVP receptor gene. (1.7 cM from D1Rat188, as determined by radiation hybrid mapping) is highlighted. 
cDNAs were isolated. A Dahl S cDNA $(\sim 1.9 \mathrm{~kb})$ and a Dahl $\mathrm{R}$ cDNA $(\sim 1.6 \mathrm{~kb})$ were subcloned into psp73 transcription vector (Promega, Madison, WI, USA) and sequenced in their entirety by the Sanger dideoxy-chain termination sequencing method using Sequenase (U.S. Biochemical, Cleveland, $\mathrm{OH}$, USA) as described previously (17). All sequences were confirmed on both strands.

Detection of the N119S and C163R Mutations by Using the Amplification Refractory Mutation System (ARMS)

The ARMS was performed using genomic DNA isolated from three Dahl S/Hsd and two Dahl R/Hsd rats essentially as described (18). The downstream primer (5'-tgc-aca-ctt-cct-gcg-ga-AC-3', Dahl S specific) specific for the N119S mutation was "destabilized" by introducing a G/A transition 1 nucleotide upstream of the 3'-OH mismatched $\mathrm{C}$ residue. Detection of allelespecific amplified products (102 bp) was done by ${ }^{32} \mathrm{P}-$ end labeling the upstream primer (5'-cac-cta-cca-gttcat-tga-cc- $3^{\prime}$ ) and subsequent size fractionation on a $6 \%$ denaturing polyacrylamide gel. The optimal stringent PCR cycling conditions experimentally determined for the N119S mutation detection were as follows: $95^{\circ} \mathrm{C}$ for $10 \mathrm{~min} ; 35$ cycles of $94^{\circ} \mathrm{C} \times 30 \mathrm{sec}$, $57^{\circ} \mathrm{C} \times 30 \mathrm{sec}, 72^{\circ} \mathrm{C} \times 1 \mathrm{~min}$; and extension at $72^{\circ} \mathrm{C} \times 7$ min. The downstream primer ( $5^{\prime}$-cac-gcc-ctg-gca-ccaca-TG-3', Dahl S specific) specific for the Cl63R mutation was "destabilized" by introducing a C/T transition 1 nucleotide upstream of the 3'-OH mismatched $\mathrm{G}$ residue. Detection of allele-specific amplified products (131 bp) was done by ${ }^{32} \mathrm{P}$-end labeling the upstream primer (5'-atg-ctc-ctg-aac-tct-gac-g-3') and subsequent size fractionation on a $6 \%$ denaturing polyacrylamide gel. The optimal stringent PCR cycling conditions experimentally determined for the C163R mutation detection were as follows: $95^{\circ} \mathrm{C}$ for $10 \mathrm{~min} ; 35$ cycles of $94^{\circ} \mathrm{C} \times 30 \mathrm{sec}, 55^{\circ} \mathrm{C} \times 30 \mathrm{sec}$, $72^{\circ} \mathrm{C} \times 1 \mathrm{~min}$; and extension at $72^{\circ} \mathrm{C} \times 7 \mathrm{~min}$. Reaction volumes were $10 \mu \mathrm{L}$, using $0.05 \mu \mathrm{mol} / \mathrm{L}$ of each primer for the C163R substitution and $0.6 \mu \mathrm{mol} / \mathrm{L}$ of each primer for the N119S substitution, $0.5 \mathrm{U} / 10 \mu \mathrm{L}$ of AmpliTaq Gold (Perkin-Elmer, Branchburg, NJ, USA), $1.5 \mathrm{mM} \mathrm{MgCl}$, and $0.2 \mu \mathrm{g}$ of genomic DNA. As control, the D1Mit13 marker (320 bp, not polymorphic between Dahl $\mathrm{S}$ and Dahl $\mathrm{R}$ strains) was used to assess equivalent amounts of genomic DNA in the different samples. To demonstrate equivalent amounts of cloned Dahl S and Dahl R AngII/AVPr cDNAs, we used a 260-bp PCR product encompassing nucleotides 378-638 (forward primer: 5'-gtt-cat-tga-cca-gag-cttcc-3'; reverse primer: $5^{\prime}$-ctt-tgt-cct-tgt-acc-cac-c- $\left.3^{\prime}\right)$ of the published Sprague-Dawley AngII/AVPr cDNA (4).

\section{Functional Analysis}

The Dahl S and Dahl R AngII/AVP receptor cDNAs were subcloned directionally ( $5^{\prime}$ to $3^{\prime}$ ) into the NheI site of the pMAMNeo expression vector (Clontech, Palo Alto, CA, USA). Stable Cos 1 neomycin-resistant transfectants were developed as described (4).
${ }^{125} \mathrm{I}$-AngII and ${ }^{3} \mathrm{H}$-AVP binding experiments were preformed essentially as described (4) on intact Cos 1 pMAM-Dahl S AngII/ AVPr and Cosl pMAM-Dahl R AngII/AVPr cell transfectants. Specific binding was determined as the difference between the total radioactivity bound to cells and the radioactivity bound to blanks containing $1 \mu \mathrm{M}$ of AngII or $10 \mu \mathrm{M}$ of AVP. AngII- and AVP-dependent stimulation of cAMP accumulation was assayed on $\mathrm{C} 127$ cell membranes after transient transfection of C127 cells (mouse mammary tumor cell line, ATCC) with the pMAM-Dahl S AngII/AVPr and the pMAM-Dahl R AngII/AVPr expression vectors. For this purpose, the pMAM-Dahl S AngII/AVP receptor and the pMAM-Dahl R AngII/ AVP receptor expression vectors (60 $\mu$ g each) were introduced into $\mathrm{C} 127$ cells $\left(10^{7}\right.$ cells) via lipofectinmediated transfection. After 5 days in culture, cells were harvested and a crude membrane preparation was obtained as described (19). $10 \mu \mathrm{g}$ of Dahl S and Dahl R AngII/AVP receptor expressing membranes were exposed to $0.1 \mu \mathrm{M}$ of AVP and $0.1 \mu \mathrm{M}$ of AngII at $25^{\circ} \mathrm{C}$ for $20 \mathrm{~min}$ with 0,50 , and $150 \mathrm{mM}$ of $\mathrm{NaCl}$, in comparison to basal control (no hormone added) in an incubation buffer containing $40 \mathrm{mM}$ of Tris- $\mathrm{HCl}$ (pH 7.6), $5 \mathrm{mM}$ of $\mathrm{MgCl}_{2}, 1 \mathrm{mM}$ of EDTA, $2 \mathrm{mM}$ of isobutylmethylxanthine, $3 \mathrm{mM}$ of ATP, $20 \mathrm{mM}$ of phosphocreatine, $5 \mathrm{U} / \mathrm{ml}$ of creatinephosphokinase, $0.1 \mu \mathrm{M}$ of GTP, and $0.1 \%$ BSA. The level of cAMP was determined by radioimmunoassay according to manufacturer's specifications (Amersham, Piscataway, NJ, USA).

\section{Results}

\section{Intercross Linkage Analysis}

To assess the potential genetic contribution of the AngII/AVP receptor gene to salt-sensitive hypertension susceptibility, we performed an intercross linkage analysis on 105 F2 (Dahl S $\delta \times$ Dahl R + ) hybrid male rats phenotyped for BP by radiotelemetry after 8 weeks of high salt $(8 \% \mathrm{NaCl})$ challenge (15). We localized the AngII/AVP receptor gene to rat chromosome 1, $1.7 \mathrm{cM}$ centromeric to the D1Rat188 marker (see Table 1) by radiation hybrid mapping analysis. Thus, 105 F2 male hybrids were genotyped at nine informative markers that spanned the AngII/AVP receptor locus on chromosome 1. As seen in Table 1, LRS and $p$ values peaked at D1Rat188 (the closest marker, $1.7 \mathrm{cM}$ to the AngII/AVP receptor locus) for SBP (LRS $=13.8, p=0.00020)$, DBP $($ LRS $=8.6, p=0.00336)$, and MAP $($ LRS $=12.4$, $p=0.00043)$. These results fulfill the first of four criteria needed to identify a hypertension susceptibility gene $(15,20)$ : 1) association of the putative hypertension susceptibility gene with hypertension in validated genetic animal models or human hypertensive patients, 2) identification of a functionally significant structural mutation in the relevant gene, 3 ) concordance of the observed molecular dysfunction with a pathophysiologic mechanism logical to the 
hypertension pathogenesis, and 4) delineation of the mechanistic role in an in vivo model. Based on a permutation test performed on the 105 informative progeny that established the minimum LRS value for highly significant as equal to 12.2 , the AngII/AVPr locus exhibits a highly significant linkage with SBP (LRS = 13.8). Analysis for interaction with $\alpha 1 \mathrm{Na}$,K-ATPase, bumetanide-sensitive $\mathrm{Na}, \mathrm{K}, 2 \mathrm{Cl}$-cotransporter and thiazide-sensitive $\mathrm{Na}$, $\mathrm{Cl}$-cotransporter loci were negative. As shown in Table 1, the AngII/AVP receptor locus accounts for $12 \%$ of the SBP variance.

\section{Molecular Analysis}

To identify molecular variants of the AngII/AVP receptor that could account for the cosegregation of the AngII/AVP receptor locus with salt-sensitive hypertension in the Dahl S rat model, we screened Dahl $S$ and Dahl R rat kidney $\lambda$ gt 11 cDNA libraries with the full-length Sprague-Dawley AngII/AVP receptor cDNA (4) as probe. Several cDNA clones were isolated and characterized. The entire amino acid coding region for both Dahl $\mathrm{R}$ and Dahl S receptors were obtained, revealing three nucleotide differences between the Dahl $R$ and Dahl $S$ AngII/AVP receptor cDNAs (Fig. 1). Two of the nucleotide changes resulted in amino acid substitutions: $A^{356}$ (Dahl R) $\rightarrow G^{356}$ (Dahl S) nucleotide transition resulting in N119S substitution localized in the first intracellular loop (Fig. 1b); $\mathrm{T}^{487}$ (Dahl R) $\rightarrow \mathrm{C}^{487}$ (Dahl S) nucleotide transition resulting in C163R substitution localized to the second extracellular loop (Fig. lb). The third $A^{627}$ (Dahl R) $\rightarrow G^{627}$ (Dahl S) nucleotide transition did not change the encoded amino acid. The nucleotide sequence encompassing the entire amino acid coding region of the Dahl R cDNA was identical to the previously reported Sprague-Dawley AngII/AVP receptor cDNA (4). The presence of N119S and C163R mutations in Dahl $\mathrm{S}$ and its absence in Dahl $\mathrm{R}$ rat genomic DNA was corroborated by error-independent amplification refractory mutation system (ARMS) detecting $\mathrm{G}^{356}$ and $\mathrm{C}^{487}$ in Dahl $\mathrm{S}$ in contrast to non$\mathrm{G}^{356}$ and non- $\mathrm{C}^{487}$ in Dahl $\mathrm{R}$ rat genomic DNA, respectively (Fig. 1c).

To elucidate potential functional differences between the Dahl S and Dahl R AngII/AVP receptors, both molecular variants were expressed in tissue culture and assayed in ligand binding experiments and hormone-dependent activation of adenylate cyclase. For this purpose, the Dahl $\mathbf{S}$ and Dahl $\mathbf{R}$ cDNA clones containing the full-length amino acid coding region of the AngII/AVP receptor were subcloned directionally $\left(5^{\prime} \rightarrow 3^{\prime}\right)$ into the NheI site of the PMAM expression vector (Clontech). Both expression vectors (pMAM-Dahl $\mathrm{R}$ AngII/AVPr and pMAM-Dahl S AngII/AVPr) were then permanently transfected into Cos I cells, and subsequently assayed for receptor function. Saturation binding studies using ${ }^{125} \mathrm{I}$-AngII and ${ }^{3} \mathrm{H}$-AVP on intact
pMAM-Dahl S and pMAM-Dahl R AngII/AVPr cell transfectants revealed significant differences in affinities for ${ }^{3} \mathrm{H}$-AVP and ${ }^{125} \mathrm{I}$-AngII binding between the Dahl $S$ and Dahl $\mathrm{R}$ receptors (Fig. 2 and Table 2). Scatchard analysis of ${ }^{125} \mathrm{I}$-AngII and ${ }^{3} \mathrm{H}-$ AVP saturation binding revealed 4.9-fold and 2.3-fold higher affinity of the Dahl $\mathrm{S}$ receptor for ${ }^{125} \mathrm{I}$-AngII and ${ }^{3} \mathrm{H}$-AVP, respectively, when compared with the Dahl R AngII/AVP receptor (Table 2). We notice that the Dahl $S$ receptor shows two distinct AngII binding sites, a high-affinity binding site $\left(\mathrm{K}_{\mathrm{H}}=0.88 \pm 0.38 \mathrm{nM}\right)$, presumably reflecting binding sites of receptors couple to G-protein, and a low-affinity binding site $\left(\mathrm{K}_{\mathrm{L}}=8.90 \pm 2.31 \mathrm{nM}\right)$ representing binding sites of receptors not coupled to G-protein. In contrast, the Dahl $\mathrm{R}$ receptors have a single AngII binding site $(\mathrm{K}=4.30 \pm 0.99 \mathrm{nM})$, further implicating a differential coupling of the Dahl $R$ receptor to $G$ protein.

To assess putative additional functional differences between the Dahl S and Dahl R AngII/AVP receptors, both expression vectors (pMAM-Dahl $S$ AngII/AVPr and pMAM-Dahl $\mathrm{R}$ AngII/AVPr) were transfected into C127 cells (mouse mammary tumor cell line [ATCC]), respectively, and membranes were isolated from transient transfectants and assayed for AVP- and AngII-induced cAMP accumulation. In earlier xenopus oocyte microinjection expression experiments, we noticed a pronounced effect of $\mathrm{NaCl}$ on the AngII-induced cAMP accumulation in isolated oocyte membrane preparations (unpublished results). Thus, we evaluated the effect of different $\mathrm{NaCl}$ concentrations on the AVP- and AngII-induced CAMP accumulation by the Dahl $S$ and Dahl $R$ receptors. As shown in Figure 3, striking differences can be observed between the Dahl S and Dahl R expressed AngII/AVP receptors. First, upon addition of $50 \mathrm{mM}$ of $\mathrm{NaCl}$, the AVP-induced cAMP accumulation increased by $14 \%$ over control levels (at $0 \mathrm{mM}$ of $\mathrm{NaCl}$ ) in Dahl $\mathrm{R}$ AngII/AVP receptor expressing membranes (from $150 \pm 7 \mathrm{pmol} / \mathrm{mg} \mathrm{Mb}$ to $171 \pm 8 \mathrm{pmol} / \mathrm{mg} \mathrm{Mb}$ ). In contrast, the addition of $50 \mathrm{mM}$ of $\mathrm{NaCl}$ produced an exaggerated response with a far greater increase $(182 \%)$ in AVP-induced cAMP accumulation in Dahl S AngII/AVP receptor expressing membranes over control levels $(0 \mathrm{mM}$ of $\mathrm{NaCl}$; from $123 \pm 6 \mathrm{pmol} / \mathrm{mg} \mathrm{Mb}$ to $347 \pm 12 \mathrm{pmol} / \mathrm{mg} \mathrm{Mb}$, Fig. 3a). Similarly, a greater response $(209 \%)$ to AngII was also observed in Dahl S versus Dahl $\mathrm{R}$ AngII/AVP receptor expressing membranes in the presence of $50 \mathrm{mM}$ of $\mathrm{NaCl}(170 \pm 11 \mathrm{pmol} / \mathrm{mg}$ $\mathrm{Mb}$ versus $55 \pm 4 \mathrm{pmol} / \mathrm{mg} \mathrm{Mb}$, Fig. $3 \mathrm{~b}$ ), respectively. This differential response is not due to differences in receptor density; similar, if not higher, AVP response $(123 \pm 6 \mathrm{pmol} / \mathrm{mg} \mathrm{Mb}$ in Dahl S versus $150 \pm 7 \mathrm{pmol} / \mathrm{mg} \mathrm{Mb}$ in Dahl $\mathrm{R}$ membranes) can be observed in Dahl $\mathbf{R}$ AngII/AVP receptor expressing membranes under control conditions (at $0 \mathrm{mM} \mathrm{NaCl}$; Fig. 3). 
a
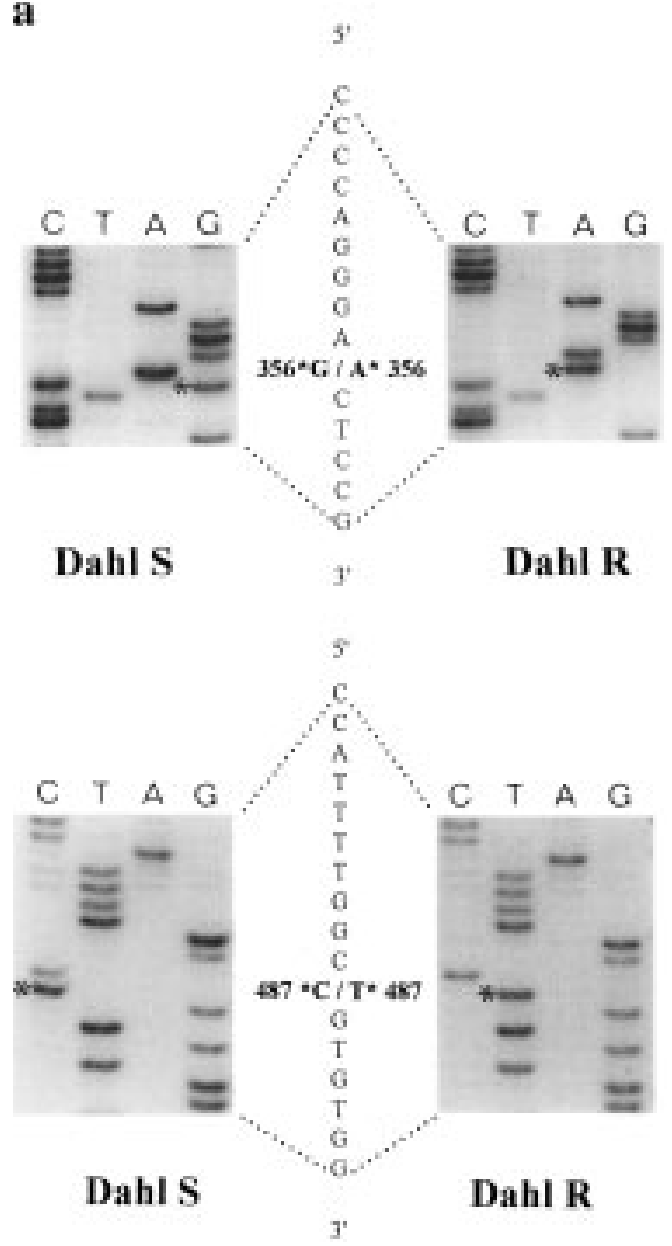

c b

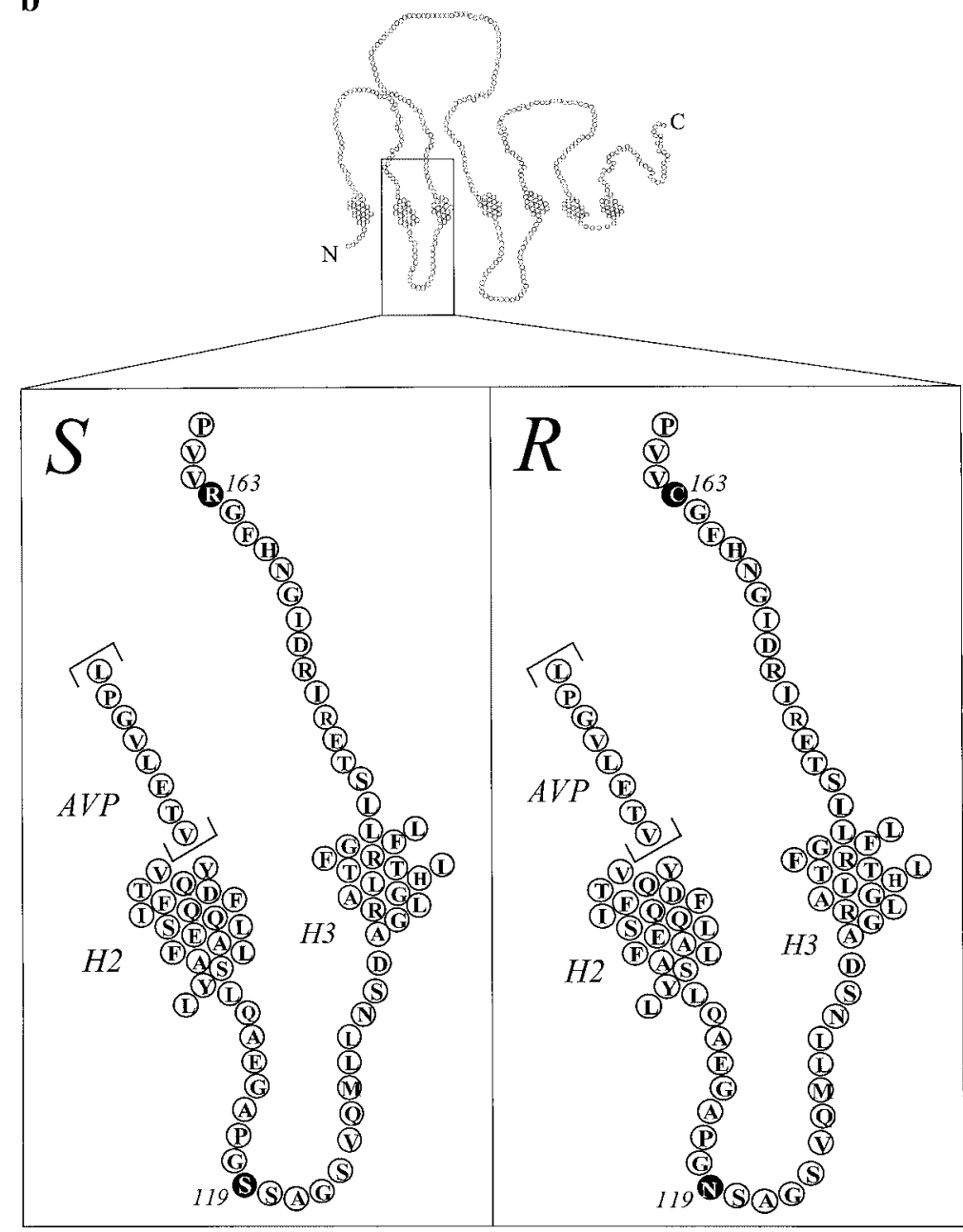

Genomic DNA

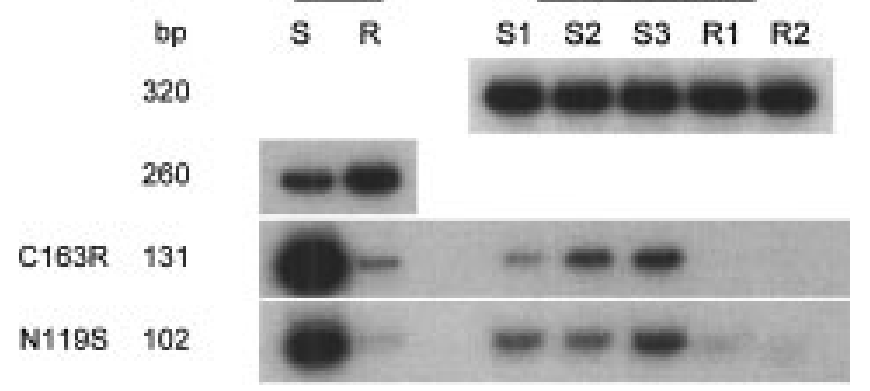

Fig. 1. Comparative analysis of nucleotide and deduced amino acid sequences of Dahl $S$ and Dahl R AngII/AVP receptor cDNAs. (a) Sequencing gels of Dahl $S$ and Dahl $R$ cDNAs spanning the $A^{356} \rightarrow G^{356}$ (Dahl $R \rightarrow$ Dahl S) nucleotide transition that results in a N119 substitution in Dahl S AngII/AVP receptor for S119 and $T^{487} \rightarrow C^{487}$ (Dahl R $\rightarrow$ Dahl S) nucleotide transition that results in a C163 substitution in Dahl S AngII/AVP receptor for R163. Nucleotide and amino acid numbering as per Ruiz-Opazo et al (4). Specific nucleotides (C, T, A, G) and 5' to 3' directions are indicated. (b) Schematic structure of the AngII/AVP receptor in the region around transmembrane domains $\mathrm{H} 2$ and H3. Open circles indicate amino acids common to both Dahl S and Dahl R AngII/AVP receptors. Black circles highlight the amino acids involved in the substitutions. (c) Detection of the N119S and C163R mutations in genomic DNA by using the amplification refractory mutation system (ARMS). ARMS analysis was designed to detect the Dahl $S$ AngII/AVP receptor gene variant, when present, by the production of an expected 102-bp (for the N119S substitution) and a 131-bp (for the C163R substitution) product, respectively. Analysis was done on three Dahl S (S1, S2, and S3) and two Dahl R (R1 and R2) genomic DNAs. Controls for the ARMS analysis were cloned Dahl S (S) and cloned Dahl R (R) AngII/AVPr cDNAs at four copies per genome equivalent. The 260-bp fragment corresponds to control PCR product showing equivalent amounts of cloned Dahl S and Dahl R AngII/AVPr cDNAs. The 320-bp fragment corresponds to control PCR product ascertaining that all genomic DNA samples amplify equivalently. The ARMS test readily detects $G^{356}$ and $C^{487}$ in Dahl S genomic DNA and their absence in Dahl R genomic DNA. 

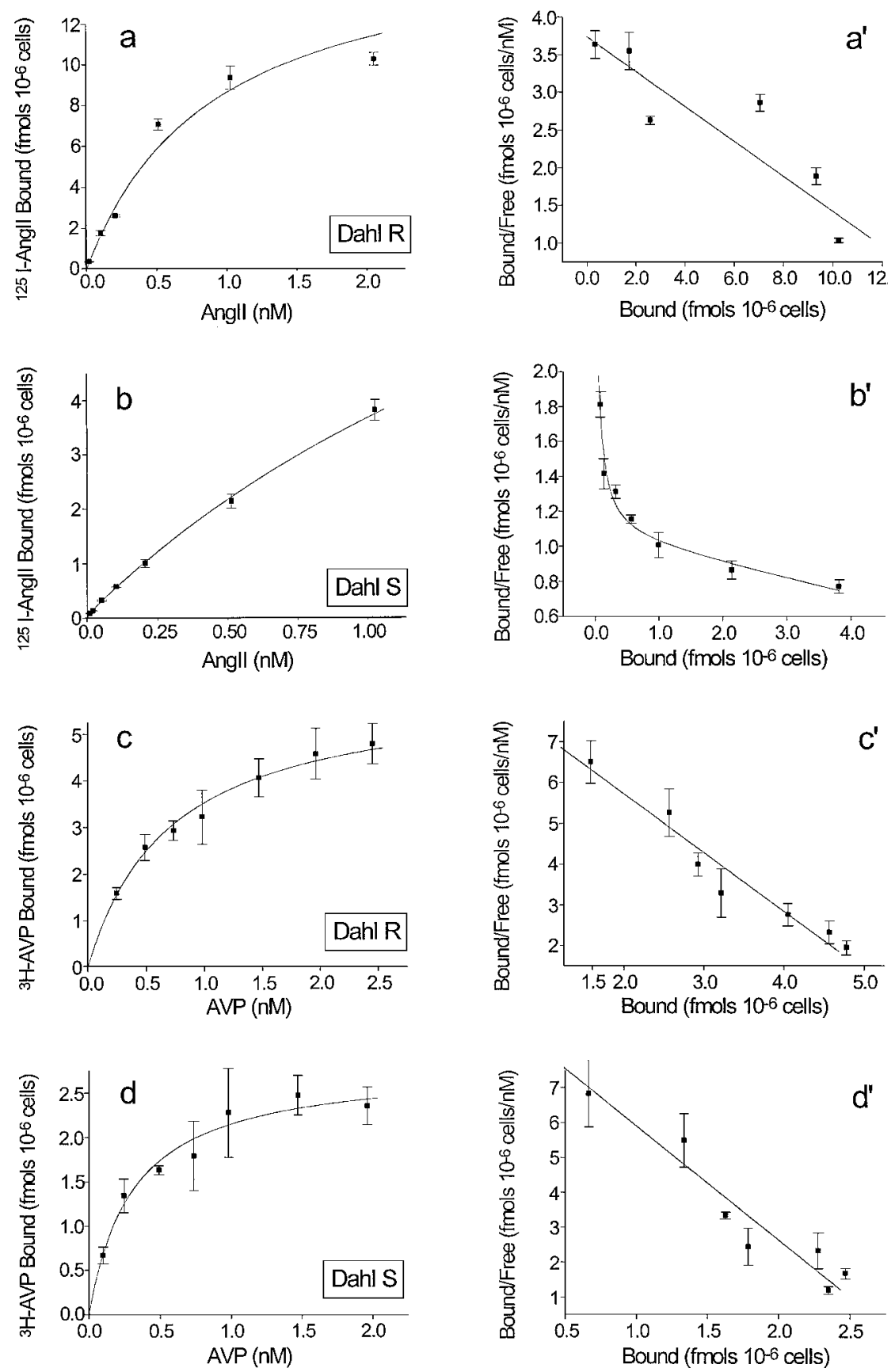

Fig. 2. Ligand binding studies of Dahl $\mathbf{R}$ and Dahl $\mathbf{S}$ AngII/AVP receptors expressed in Cosl cells. Saturation binding curves $(\mathbf{a}, \mathbf{b}, \mathbf{c}, \mathbf{d})$ and corresponding Scatchard plots $\left(\mathbf{a}^{\prime}, \mathbf{b}^{\prime}, \mathbf{c}^{\prime}, \mathbf{d}^{\prime}\right)$ with ${ }^{125} \mathrm{I}$-AngII $(\mathbf{a}, \mathbf{b})$ and $\left[{ }^{3} \mathrm{H}\right]$-AVP $(\mathbf{c}, \mathbf{d})$ in Dahl R $(\mathbf{a}, \mathbf{c})$ and Dahl S $(\mathbf{b}, \mathbf{d})$ AngII/AVP receptors expressed in permanent Cosl cell transfectants. Each experiment was performed in quadruplicate. Values are presented as mean \pm standard deviation.

\section{Discussion}

Our studies have detected a modulator effect of sodium on G-protein coupling, a unique feature of the AngII/AVP receptor function that could have a significant impact on modulation of receptor function under physiologic conditions. Whereas AVP-dependent activation of cAMP accumulation (presumably via $\mathrm{G}_{\mathrm{s}}$-receptor coupling) is minimally affected by sodium in the wild-type (Dahl $\mathrm{R}$ ) receptor, the AngII-dependent activation of cAMP accumulation is dramatically influenced by sodium in both Dahl S and Dahl $\mathrm{R}$ receptors resulting in a dichotomous sodium effect. Inhibition of AngII-induced cAMP accumulation (presumably via $\mathrm{G}_{\mathrm{i}}$-receptor coupling) is observed in the absence of sodium, whereas stimulation of AngII-induced cAMP accumulation 
Table 2. AngII and AVP binding parameters of Dahl S and Dahl R AngII/AVP receptors

\begin{tabular}{|c|c|c|c|c|c|}
\hline $\begin{array}{l}\text { AngII/AVP } \\
\text { Receptor }\end{array}$ & $\begin{array}{c}K_{\mathbf{H}} \text { AngII } \\
(\mathbf{n M})\end{array}$ & $\begin{array}{c}B_{\text {MAXX }}(\mathrm{fmol} \\
\left.10^{-6} \text { cells }\right)\end{array}$ & $\begin{array}{c}K_{\mathrm{L}} \text { AngII } \\
(\mathrm{nM})\end{array}$ & $\begin{array}{c}B_{\text {MAX }} \text { (fmol } \\
10^{-6} \text { cells) }\end{array}$ & $\underset{(\mathbf{n M})}{K_{\mathbf{H}} \mathrm{AVP}}$ \\
\hline Dahl S & $0.88 \pm 0.38$ & $1.50 \pm 0.54$ & $8.90 \pm 2.31$ & $10.40 \pm 2.18$ & $0.30 \pm 0.04$ \\
\hline Dahl R & $4.30 \pm 0.99$ & $16.40 \pm 2.72$ & ND & ND & $0.70 \pm 0.08$ \\
\hline
\end{tabular}

Scatchard analysis (RADLIG, Version 4 Program, McPherson) of the $\left[{ }^{3} \mathrm{H}\right]$-AVP and ${ }^{125}$ I-labeled AngII saturation curves (Fig. 3) was performed. $K_{\mathrm{H}}$. high affinity $\left(\mathrm{nM} \pm\right.$ error); $K_{\mathrm{L}}$, low affinity $(\mathrm{nM} \pm$ error); ND, nondetected.

(presumably via $\mathrm{G}_{\mathrm{s}}$-receptor coupling) is observed in the presence of sodium (see Fig. 3).

Sodium modulation of receptor function is not without precedent. Allosteric regulation of $\alpha 2$ adrenergic receptor ligand binding by sodium has been reported (21) in which the allosteric effects of sodium have been found to be maximal at $40 \mathrm{mM}$ (21). This is similar to the maximal effect of sodium on AngII/AVP receptor function detected at $50 \mathrm{mM}$ (see Fig. 3). Altogether, the data suggest that the

a

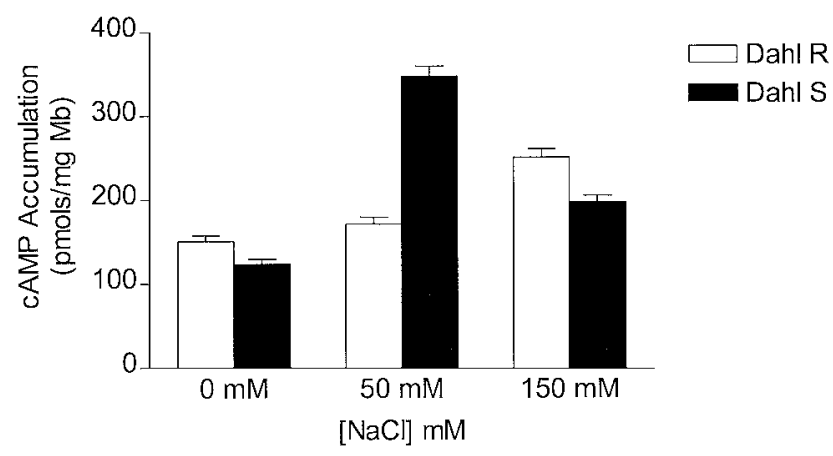

b

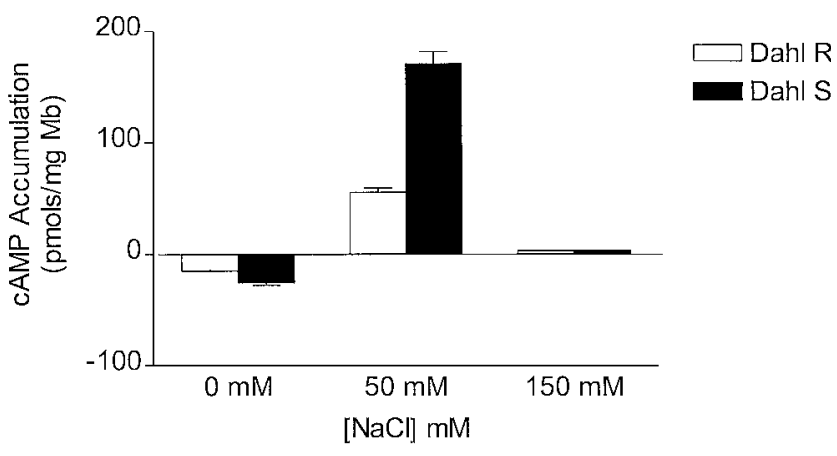

Fig. 3. Hormone-dependent stimulation of cAMP accumulation in Dahl S and Dahl $R$ AngII/AVP receptors expressed in $\mathbf{C 1 2 7}$ cells. Ten micrograms of Dahl S and Dahl R AngII/AVP receptor expressing membranes were exposed to $0.1 \mu \mathrm{M}$ of AVP (a) or $0.1 \mu \mathrm{M}$ of AngII (b) at $25^{\circ} \mathrm{C}$ for $20 \mathrm{~min}$ in the presence of 0,50 , or $150 \mathrm{mM}$ of $\mathrm{NaCl}$, in comparison to basal control (no hormone added). Each experiment was performed in triplicate. Values are presented as mean \pm standard deviation. sodium modulation of AngII/AVP receptor function is a biologically significant phenomenon that contributes to susceptibility to salt-sensitive hypertension in the Dahl S rat model. Furthermore, we hypothesize that this receptor could be a key component of a sodium-sensing gene network underlying physiologic regulation of sodium homeostasis. It is important to note that the AngII/AVP receptor is broadly expressed in neurons of the central nervous system, including those regions thought to be involved in central control of blood pressure and salt appetite $(22,23)$. However, additional molecular, cellular, and physiologic studies are necessary to test this hypothesis.

The differential effects of sodium on AngII- and AVP-induced CAMP accumulation indicate that the AngII/AVP receptor mediates AngII and AVP stimulation via two distinct effector pathways. Moreover, it also documents alternative use of guanine nucleotidebinding regulatory proteins by a single receptor as a mechanism for diversifying receptor function. The sodium-dependent "switching" of the AngII/AVP receptor from $G_{i}$ to $G_{s}$ coupling observed in our studies, resembles the PKA-dependent "switching" from $G_{s}$ to $\mathrm{G}_{\mathrm{i}}$ coupling recently reported in the $\alpha 2$-adrenergic receptor (24), thus corroborating the existence of multiple G-protein coupling "switching" mechanisms.

The localization of the amino acids substitutions within the Dahl S receptor suggests that they may differentially influence receptor function. The N119S substitution in the $\mathrm{H} 2-\mathrm{H} 3$ intracellular loop (see Fig. 1b) could affect $G_{S}$ coupling because of its proximity to the putative $G_{S}$ activation domain (H4-H5 intracellular loop, see Fig. 1b). In contrast, the C163R substitution in the $\mathrm{H} 3-\mathrm{H} 4$ extracellular loop (see Fig. 1b) might influence AVP and AngII binding due to its putative effects on the secondary structure of the extracellular receptor domains.

Our results demonstrate the existence of a "hyperfunctioning" AngII/AVP receptor present in Dahl salt-sensitive rats exhibiting increased affinity for both ligands (AVP and AngII) and enhanced $G_{S}$ coupling resulting in increased activation of adenylate cyclase. Analogous dysfunctional behavior has been reported for the constitutively activated mutation of the luteinizing hormone receptor in familial 
male precocious puberty (25) and in thyrotropin receptor involved in thyroid adenomas (26). Thus, for any given level of ligand (AVP or AngII) concentrations, the "hyperfunctional" Dahl S AngII/AVP receptor will effectively produce a higher level of cAMP accumulation compared with the Dahl R receptor. Intuitively, we hypothesize that this AngIIAVP "hyperresponse" could contribute to increased tubular sodium and fluid reabsorption in Dahl S rats, a characteristic pathophysiology observed in this genetic hypertensive rat model (3). Our hypothesis is substantiated by the prominent expression of the AngII/AVP receptor in the thick ascending limb of the loop of Henle and collecting ducts (5).

We note that several genetic studies in different rat models have documented a chromosome 1 quantitative trait locus (QTL) in the region spanning the AngII/AVP receptor locus for high blood pressure (27-37). Reports include intercross linkage analysis of F2 cohorts derived from SHRSP (stroke-prone spontaneously hypertensive rat) $\times$ WKY (WistarKyoto normotensive rat) $(27,28)$, SHR (spontaneously hypertensive rat) $\times$ WKY (29), SS/JR (Dahl saltsensitive hypertensive rat) $\times$ LEW (Lewis normotensive rat) (32), FHH (Fawn-hooded hypertensive rat) $\times$ ACI (ACI normotensive rat) (31) and SBH/y (saltsensitive Sabra hypertension-prone rat) $\times$ SBN $/ y$ (salt-resistant Sabra hypertension resistant rat) (37). Based on recent evidence excluding $\mathrm{Sa}$ as a candidate gene for the blood pressure QTL on rat chromosome $1(35,36)$, our results, in conjunction with the available genetic evidence, point to the AngII/AVP receptor as the candidate gene for the chromosome l QTL in different rat models of essential hypertension. Strategic transgenic experiments will be necessary to demonstrate the mechanistic role of the AngII/AVP receptor in salt-sensitive hypertension.

Most importantly, the selective AngII-dependent sodium hyperresponsiveness of the dual AngII/AVP receptor is concordant with studies in humans demonstrating the central role of the renin-angiotensin system (RAS) in salt-sensitive blood pressure response (38). Altogether the data provide a compelling basis and strategic focus for investigating the role of the AngII/AVP receptor in human hypertension.

\section{Acknowledgments}

We thank Greg Prado and Alec Goodman for excellent technical support and Ari Tsikoudakis for manuscript preparation. This study was supported by NIH HL6007l.

\section{References}

1. Dahl LK, Heine L, Tassinari L. (1972) Role of genetic factors in susceptibility to experimental hypertension due to chronic excess salt ingestion. Nature 194: 480-482.

2. Dahl LK, Heine M, Thompson K. (1974) Genetic influence of the kidneys on blood pressure: evidence from chronic renal homografts in rats with opposite predispositions to hypertension. Circ. Res. 34: 94-101.
3. DeWardener HE. (1990) The primary role of the kidney and salt intake in the aetiology of essential hypertension, part II. Clin. Sci. 79: 289-297.

4. Ruiz-Opazo N, Akimoto K, Herrera VLM. (1995) Identification of a novel dual angiotensin II/vasopressin receptor on the basis of molecular recognition theory. Nat. Med. 1: 1074-1081.

5. Gonzalez CB, Herrera VLM, Ruiz-Opazo N. (1997) Renal immunocytochemical distribution and pharmacologic properties of the dual AngII/AVP receptor. Hypertension 29: 957-961.

6. Morel F, Imbert-Teboul M, Chabardes D. (1987) Receptors to vasopressin and other hormones in the mammalian kidney. Kidney Int. 31: 512-520.

7. Jard S. (1983) Vasopressin isoreceptors in mammals: relation to cyclic AMP-dependent and cyclic AMP-independent transduction mechanisms. Curr. Top. Mem. Transp. 18: 225-285.

8. Barraclough MA, Jones NF, Marsden CD. (1967) Effect of angiotensin on renal function in the rat. Am. J. Physiol. 212: 1153-1157.

9. Hall JE. (1986) Control of sodium excretion by angiotensin II: intrarenal mechanisms and blood pressure regulation. Am. J. Physiol. 250: R960-R972.

10. Harris PJ, Young JA. (1977) Dose-dependent stimulation and inhibition of proximal tubular sodium reabsorption by angiotensin II in the rat kidney. Pflugers Arch. 367: 295-297.

11. Harris PJ, Navar LG. (1985) Tubular transport responses to angiotensin. Am. J. Physiol. 248: F62 1-F630.

12. Johnson MD, Malvin RL. (1977) Stimulation of renal sodium reabsorption by angiotensin II. Am. J. Physiol. 232: F298-F306.

13. Mitchell KD, Navar LG. (1990) Interactive effects of angiotensin II on renal hemodynamics and tubular reabsorptive function. Kidney Int. (suppl 30): 569-573.

14. Navar LG, Langford HG. (1974) Effects of angiotensin on the renal circulation. In: Page IH, Bumpus FM, eds. Angiotensin, Handbuch der exp Pharmakol, pp. 455-474.

15. Herrera VLM, Xie HX, Lopez LV, Schork NJ, Ruiz-Opazo N. (1998) The $\alpha 1 \mathrm{Na}$,K-ATPase gene is a susceptibility hypertension gene in the Dahl salt-sensitive ${ }^{\mathrm{HSD}}$ rat. J. Clin. Invest. 102: 1102-1111.

16. Meer JM, Cudmore RH, Manly KF. (2000) Map manager QTXb08, version 9/25/2000, University at Buffalo, The State University of New York, Buffalo, NY.

17. Herrera VLM, Ruiz-Opazo N. (1990) Alteration of $\alpha 1 \mathrm{Na}$, $\mathrm{K}$-ATPase ${ }^{86} \mathrm{Rb}^{+}$influx by a single amino acid substitution. Science 249: 1023-1026.

18. Newton CR, Graham A, Heptinstall LE, et al. (1989) Analysis of any point mutation in DNA. The amplification refractory mutation system (ARMS). Nucleic Acids Res. 17: 2503-2516.

19. Takuwa Y, Kasuya Y, Takuwa N, et al. (1990) Endothelin receptor is coupled to phospholipase $C$ via a pertussis toxininsensitive guanine nucleotide-binding regulatory protein in vascular protein in vascular smooth muscle cells. J. Clin. Invest. 85: 653-658.

20. Herrera VLM, Ruiz-Opazo N. (1991) Genetics of hypertension: a multidisciplinary challenge. Trends Cardiovasc. Med. 1: 185-189.

21. Horstman DA, Brandon S, Wilson AL, Guyer CA, Cragoe EJ, Limbird LE. (1990) An aspartate conserved among G-protein receptors confers allosteric regulation of $\alpha 2$-adrenergic receptors by sodium. J. Biol. Chem. 265: 21590-21595.

22. Hurbin A, Orcel H, Ferraz C, Moos FC, Rabie A. (2000) Expression of the genes encoding the vasopressin-activated calcium-mobilizing receptor and the dual angiotensin II/ vasopressin receptor in the rat central nervous system. J. Neuroendocrinol. 12: 677-684.

23. Wright JW, Harding JW. (1992) Regulatory role of brain angiotensins in the control of physiological and behavioral responses. Brain Res. Rev. 17: 227-262.

24. Daaka Y, Luttrell LM, Lefkowitz RJ. (1997) Switching of the coupling of the $\beta_{2}$-adrenergic receptor to different G-proteins by protein kinase A. Nature 80: 88-91.

25. Shenker A, Lane L, Kosugi S, Merendino JJ, Minegishi T, Cutler GB. (1993) A constitutively activating mutation of the luteinizing hormone receptor in familial male precocious puberty. Nature 365: 652-654. 
26. Parma J, Duprez L, Van Sande J, et al. (1993) Somatic mutations in the thyrotropin receptor gene cause hyperfunctioning thyroid adenomas. Nature 365: 649-651.

27. Nabika T, Nara Y, Ikeda K, Endo J, Yamori Y. (1993) A new genetic locus cosegregating with blood pressure in F2 progeny obtained from stroke-prone spontaneously hypertensive rats and Wistar-Kyoto rats. J. Hypertens. 11: 13-18.

28. Nara Y, Nabika T, Ikeda K, et al. (1993) Basal high blood pressure cosegregates with the loci on chromosome 1 in the F2 generation from crosses between normotensive Wistar Kyoto rats and stroke-prone spontaneously hypertensive rats. Biochem. Biophys. Res. Commun. 194: 1344-1351.

29. Samani NJ, Lodwick D, Vincent M, et al. (1993) A gene differentially expressed in the kidney of the spontaneously hypertensive rat cosegregates with increase blood pressure. J. Clin. Invest. 92: 1099-1103.

30. Harris EL, Dene H, Rapp JP. (1993) SA gene and blood pressure cosegregation using Dahl salt-sensitive rats. Am. J. Hypertens. 6: 330-334.

31. Brown DM, Provoost AP, Daly MJ, Lander ES, Jacob HJ. (1996) Renal disease susceptibility and hypertension are under independent genetic control in the fawn-hooded rat. Nat. Genet. 12: 44-51.
32. Gu L, Dene H, Deng AY, et al. (1996) Genetic mapping of two blood pressure quantitative trait loci on rat chromosome 1. J. Clin. Invest. 97: 777-788.

33. St. Lezin E, Griffin KA, Picken M, et al. (1997) Genetic isolation of a chromosome 1 region affecting blood pressure in the spontaneously hypertensive rat. Hypertension 30: 854-859.

34. Frantz SA, Kaiser M, Gardiner SM, et al. (1998) Successful isolation of a rat chromosome 1 blood pressure quantitative trait locus in reciprocal congenic strains. Hypertension 32: 639-646.

35. Hubner N, Lee Y-A, Lindpaintner K, Ganten D, Kreutz R. (1999) Congenic substitution mapping excludes $\mathrm{Sa}$ as a candidate gene locus for a blood pressure quantitative trait locus on rat chromosome 1. Hypertension 34: 643-648.

36. St. Lezin E, Liu W, Wang JM, et al. (2000) Genetic analysis of rat chromosome 1 and the $S a$ gene in spontaneous hypertension. Hypertension 35: 225-230.

37. Yagil C, Sapojnikov M, Kreutz R, et al. (1998) Salt susceptibility maps to chromosomes 1 and 17 with sex specificity in the Sabra rat model of hypertension. Hypertension 31: 119-124.

38. Cowley Jr AW. (1997). Genetic and nongenetic determinants of salt sensitivity and blood pressure. Am. J. Clin. Nutr. 65(suppl): 587S-593S. 